\title{
KESIAPAN PENDIDIK PAUD DALAM MENGAJAR ANAK USIA DINI DI KOTA BANDUNG
}

\author{
Oleh: Lisna Sulinar Sari*
}

\begin{abstract}
The research was conducted aimed at finding out about the readiness of PAUD educators in teaching seen from: 1) recruitment of PAUD educators provided by PAUD managers in the city of Bandung; and 2) academic qualifications and competencies of PAUD educators in the city of Bandung. This research was conducted with a qualitative approach. Respondents are principals or managers of PAUD and PAUD educators in the city of Bandung. Data were obtained throught focus group discussion, and questionnaire. The results showed that the recruitment of PAUD educators was conducted in various ways, such as making announcements, making classified advertisements in newspapers, there were also job seekers coming directly to PAUD institutions to register as PAUD educators, and even looking through the help of friends. There are still many academic qualifications for early childhood education in the city of Bandung, but for TPA all PAUD educators are already undergraduates, but there are those who are S2 but non-educational scholars. The competencies possessed by PAUD educators are also different. The competence of TK, KB and SPS educators mostly reaches the level of affordability, but there are a small number of TPA educators who have disabilities in pedagogic competencies. The aspects of pedagogic competence that cannot be mastered by TPA teachers are, they are unable to carry out remedial and enrichment programs.
\end{abstract}

Keywords: academic qualifications, competence, PAUD educators.

\begin{abstract}
ABSTRAK
Penelitian ini dilakukan bertujuan untuk mengetahui tentang kesiapan pendidik PAUD dalam mengajar dilihat dari: 1) rekrutmen penyediaan pendidik PAUD yang dilakukan oleh pengelola PAUD di Kota Bandung; dan 2) kualifikasi akademik dan kompetensi pendidik PAUD di Kota Bandung. Penelitian ini dilakukan dengan pendekatan kualitatif. Responden adalah kepala sekolah atau pengelola PAUD dan pendidik PAUD, dan di Kota Bandung. Pengumpulan data dilakukan dengan FGD dan pemberian kuesioner. Hasil penelitian menunjukan bahwa rekrutmen penyediaan pendidik PAUD dilakukan dengan beragam cara, seperti membuat pengumuman, membuat iklan baris di Koran, ada juga yang pencari kerja datang langsung ke lembaga PAUD untuk mendaftar menjadi pendidik PAUD, dan bahkan mencari melalui bantuan teman. Kualifikasi akademik pendidika PAUD di Kota Bandung masih banyak yang berada di bawah standard, tapi untuk TPA semua pendidik PAUDnya sudah sarjana, namun ada yang S2 tetapi sarjana
\end{abstract}

*Peneliti di Pusat Penelitian Kebijakan Pendidikan dan Kebudayaan Badan Penelitian dan Pengembangan Kementerian Pendidikan dan Kebudayaan. Email: 1isnapuslit@gamail.com 
non kependidikan. Kompetensi yang dimiliki oleh pendidik PAUD juga berbeda. Kompetensi pendidik TK, KB dan SPS sebagian besar mencapai tingkat mampu, namu ada sebagian kecil pendidik TPA yang memiliki ketidakmampuan dalam kompetensi pedagogic. Aspek kompetensi pedagogic yang tidak mampu dikuasai oleh guru TPA yaitu, tidak mampu dalam melaksanakan program remedial dan pengayaan.

Kata Kunci: Kualifikasi akademik, kompetensi, pendidik PAUD.

\section{PENDAHULUAN}

Anak merupakan asset yang penting untuk masa depan suatu bangsa. Kemajuan suatu bangsa dapat dilihat dari keberhasilan pendidikannya. Pendidikan merupakan usaha sadar dan terencana untuk mewujudkan suasana belajar dan proses pembelajaran yang nyaman agar peserta didik secara aktif dapat mengembangkan potensi dirinya untuk memiliki kekuatan spiritual keagamaan, pengendalian diri, kepribadian, kecerdasan, akhlak mulia, serta keterampilan yang diperlukan dirinya, masyarakat, bangsa, dan negara. Salah satu pendidikan yang dapat menjadikan seseorang mencapai keberhasilan dalam menempuh pendidikan selanjutnya adalah pendidikan anak usia dini (PAUD).

PAUD merupakan upaya pembinaan yang ditujukan kepada anak sejak lahir sampai dengan usia 6 (enam) tahun yang dilakukan melalui pemberian rangsangan pendidikan untuk membantu pertumbuhan dan perkembangan jasmani dan rohani agar anak memiliki kesiapan dalam memasuki pendidikan lebih lanjut. PAUD memegang peranan penting untuk menyiapkan generasi penerus bangsa yang memiliki akhlak mulia, cerdas, tangguh, dan dapat bersaing dikancah internasional. Mengapa PAUD penting, karena pada masa itu merupakan masa keemasan (golden age), dimana perkembangan otak anak usia dini sedang berkembang dengan pesat, begitu pula dengan tumbuh kembangnya. Anak usia dini dapat berkembang optimal jika mendapatkan stimulasi yang baik dan benar. Untuk memberikan stimulasi yang baik dan benar diperlukan seorang pendidik anak usia dini yang paham tentang PAUD agar potensi anak usia dini dapat berkembang secara optimal.

Pendidik anak usia dini merupakan tenaga professional yang bertugas merencanakan, melaksanakan pembelajaran, dan menilai hasil pembelajaran, serta melakukan pembimbingan, pelatihan, pengasuhan, dan perlindungan. Dalam standard 
nasional PAUD dijelaskan bahwa, pendidik anak usia dini terdiri atas guru PAUD, guru pendamping, dan guru pendamping muda. Pada umumnya guru PAUD dan guru pendamping ada dalam satuan PAUD (TK, KB, TPA, dan SPS), kecuali di TPA ada penambahan guru pendamping muda di mana TPA memberikan layanan pengasuhan kepada anak usia dini.

Guru memiliki peran strategis yaitu sebagai tenaga professional dan agen pembelajaran. Guru sebagai tenaga professional, dimana pekerjaan guru hanya dapat dilakukan oleh seseorang yang memiliki kualifikasi akademik, kompetensi, dan sertifikat pendidik sesuai dengan persyaratan untuk setiap jenis dan jenjang pendidikan tertentu. Guru sebagai agen pembelajaran terkait dengan peran guru dalam pembelajaran, yaitu sebagai fasilitator, motivator, pemacu, perekayasa pembelajaran, dan pemberi inspirasi belajar bagi peserta didik. Guru adalah fasilitator utama di sekolah yang berfungsi untuk menggali, mengembangkan, dan mengoptimalkan potensi yang dimiliki anak seperti agama dan moral, fisik motoric, kognitif, bahasa, social emosional, dan seni. Melalui guru, peserta didik dapat memperoleh transfer ilmu pengetahuan dan pemahaman yang dibutuhkan untuk mengembangkan potensi dirinya.

Kinerja guru berhubungan dengan proses belajar mengajar, yaitu kemampuan atau kecakapan seorang guru dalam pembelajaran dengan menciptakan suasana komunikasi yang edukatif antara guru dan peserta didik yang mencakup kognitif, efektif, dan psikomotorik sebagai upaya mempelajari sesuatu berdasarkan perencanaan sampai dengan tahap evalualusi dan tindak lanjut agar mencapai tujuan pengajaran. Kinerja mengajar guru mencakup kualitas, tingkat keahlian, latar belakang budaya dan pendidikan, kemampuan dan sikap, minat dan motivasi, disiplin, etos kerja, struktur pekerjaan, keahlian, serta umur dari angkatan kerja. Selain itu, guru harus memiliki kemampuan untuk membuat perencanaan pengajaran, menuliskan tujuan pengajaran, menyajikan bahan pelajaran, memberikan pertanyaanpertanyaan kepada peserta didik, mengajarkan konsep-konsep, berkomunikasi yang baik dengan peserta didik, mengamati kelas untuk melihat karakateristik peserta didik, dan mengevaluasi hasil belajar dari peserta didik. Kemampuan mengajar guru menjadi sangat penting dan harus dimiliki oleh guru dalam mengembankan 
tugas dan fungsi guru. Semuanya kembali kepada pribadi guru masing-masing.

Jumlah pendidik PAUD yang terdapat di Kota Bandung pada tahun 2016 sebanyak 7.695 orang yang terdiri dari 44 orang PNS dan 7.651 Non PNS. Kualifikasi akademik yang dimiliki oleh pendidik PAUD Kota Bandung sebanyak $56,60 \%$ adalah lulusan SMA sederajat, yang lainnya adalah S1, S2, dan D3. Untuk lebih jelasnya dapat dilihat pada Tabel 1.1. 
Tabel 1.1. Jumlah Pendidik PAUD berdasarkan satuan PAUD, status pegawai, kualifikasi akademik, dan jumlah pendidik PAUD yang sudah memiliki sertifikasi di Kota Bandung pada tahun 2016

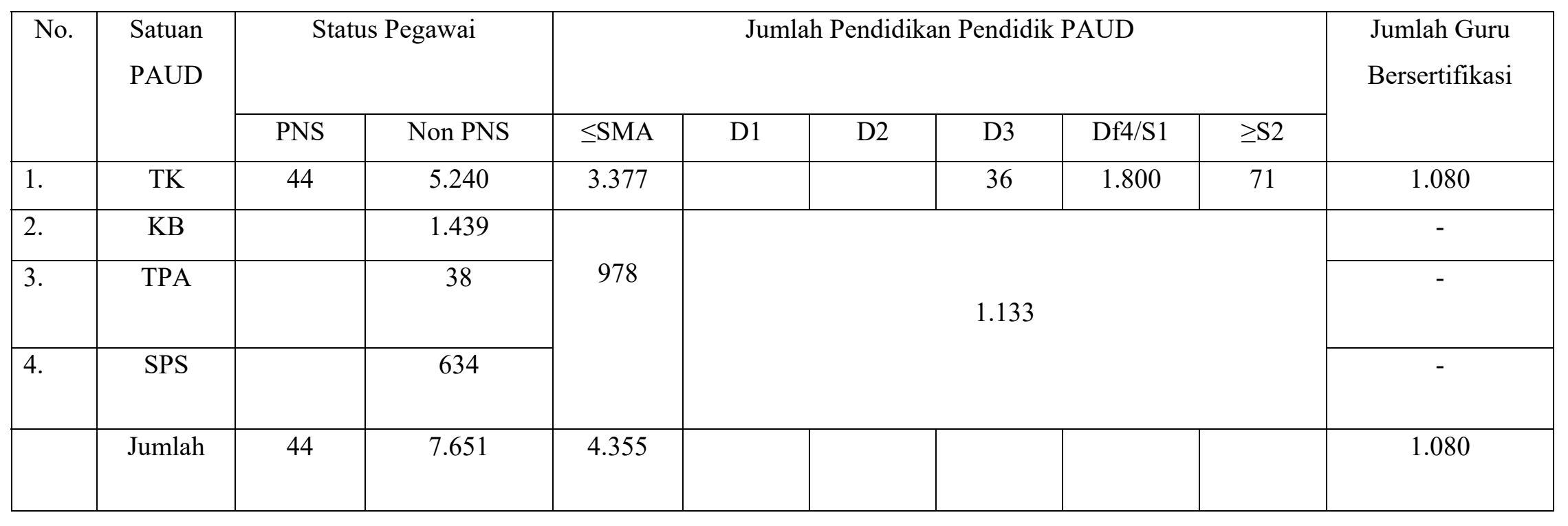


Berdasarkan standard nasional PAUD, untuk menjadi seorang pendidik PAUD harus memiliki kualifikasi akademik dan kompetensi yang dipersyaratkan pada Standar nasional PAUD. Jika kualifikasi akademik tidak sesuai dengan ketentuan yang berlaku, maka lembaga PAUD tersebut belum memenuhi standard pendidik dan tenaga kependidikan yang terdapat dalam standard nasional PAUD. Kompetensi yang harus dimiliki oleh pendidik PAUD, yakni guru PAUD dan guru pendamping adalah komptensi pedagogic, professional, kepribadian, dan social. Keempat kompotensi ini harus dikuasi dan dipahami oleh pendidik PAUD demi kelancaran dalam kegiatan belajar mengajar di kelas. Sedangkan untuk guru pendamping muda, kompetensii yang harus dikuasai dan dipahami adalah dasar-dasar pengasuhan. Sebagai contoh di TPA memberikan layanan pengasuhan, karena TPA adalah tempat penitipan anak, sehingga banyak anak-anak balita yang dititipkan hingga sore yang disebabkan orang tuanya bekerja. Layanan yang diberikan di TPA selain layanan pendidikan ada layanan pengasuhan, karena ada TPA yang menerima anak usia dini sejak usia 3 bulan sampai 6 tahun. Untuk lebih jelasnya lihat Tabel 1.2 berikut ini. 
Tabel 1.2. Persyaratan untuk menjadi pendidik PAUD berdasarkan SN PAUD

\begin{tabular}{|l|l|l|}
\hline Pendidik PAUD & \multicolumn{1}{|c|}{ Kualifikasi } & \multicolumn{1}{|c|}{ Kompetensi } \\
\hline 1. Guru PAUD & $\begin{array}{l}\text { S1 PAUD atau S1 Kependidikan } \\
\text { yang relevan atau S1 Psikologi, } \\
\text { untuk S1 Kependidikan yang } \\
\text { relevan dan S1 PAUD harus } \\
\text { mengikuti Pendidikan Profesi Guru } \\
\text { (PPG) }\end{array}$ & $\begin{array}{l}\text { Kompetensi Pedagogik, } \\
\text { Profesional, } \\
\text { Kepribadian, dan Sosial }\end{array}$ \\
\hline 2. Guru & $\begin{array}{l}\text { S1 PAUD atau S1 Kependidikan } \\
\text { yang relevan atau S1 Psikologi, } \\
\text { untuk S1 Kependidikan yang } \\
\text { relevan atau D2 PG-TK dan } \\
\text { memiliki sertifikat pelatihan/ } \\
\text { pendidikan/kursus PAUD jenjang } \\
\text { Guru Pendamping }\end{array}$ & $\begin{array}{l}\text { Pompetensi Pedagogik, } \\
\text { Profesional, } \\
\text { Kepribadian, dan Sosial }\end{array}$ \\
\hline $\begin{array}{l}\text { SMA atau sederajat memiliki serti- } \\
\text { Pendamping } \\
\text { Muda }\end{array}$ & $\begin{array}{l}\text { fikat pelatihan/pendidikan/kursus } \\
\text { PAUD jenjang pengasuh }\end{array}$ & $\begin{array}{l}\text { Kompetensi Guru Pen- } \\
\text { damping mencakup } \\
\text { pemahaman dasar-dasar } \\
\text { pengasuhan, } \\
\text { keterampilan } \\
\text { melaksanakan pengasuh- } \\
\text { an, bersikap dan perilaku } \\
\text { sesuai dengan kebutuhan } \\
\text { tingkat usia anak }\end{array}$ \\
\hline
\end{tabular}


Berdasarkan uraian di atas, maka dapat dirumuskan permasalahan sebagai berikut:1) Bagaimana rekrutmen penyediaan pendidik PAUD oleh pengelola PAUD di Kota Bandung?; dan 2) Bagaimana kualifikasi akdemik dan kompetensi pendidik PAUD di Kota Bandung?

Tujuan dari penelitian ini adalah untuk:

1) Mengetahui rekrutmen penyediaan pendidik PAUD oleh pengelola PAUD di Kota Bandung; dan 2) Mengetahui kualifikasi akademik dan kompetensi pendidik PAUD di Kota Bandung.

\section{KAJIAN TEORI}

Menurut Slameto (2010:113), kesiapan merupakan keseluruhan kondisi seseorang yang membuatnya siap untuk memberikan respon atau jawaban dalam cara tertentu terhadap suatu situasi. Penyesuaian kondisi pada suatu saat akan berpengaruh atau kecenderungan untuk memberi respon. Hamalik (2006:41) berpendapat, bahwa kesiapan adalah keadaan kapasitas yang ada pada diri siswa dalam hubungan dengan tujuan pengajaran tertentu. Kesiapan menurut Kuswahyuni, (2009:27), adalah suatu tindakan yang dilakukan seseorang untuk merancang sesuatu.

Berdasarkan definisi di atas, maka kesiapan adalah keseluruhan kondisi seseorang yang membuatnya siap untuk memberikan respon atau jawaban, merancang sesuatu dengan tujuan tertentu. Jadi kesiapan mengajar pendidik PAUD, yaitu keseluruhan kondisi pendidik PAUD yang siap untuk memberikan respon atau jawaban kepada siswa dengan merancang pembelajaran sesuai dengan tujuan pengajaran yang ditetapkan oleh pendidik PAUD.

Keberadaan guru/pendidik sangat terkait dengan keberhasilan dan kualitas pendidikan. Guru adalah pribadi yang harus mampu menerjemahkan dan menjabarkan nilai-nilai yang terdapat dalam kurikulum, kemudian menstransformasikannya kepada peserta didik melalui proses pembelajaran di dalam ruang kelas. Guru/pendidik tidak membuat kurikulum, tapi guru/pendidik menggunakan, menjabarkannya, dan melaksanakannya melalui proses pembelajaran bagi peserta didik. Secara nyata guru memberikan pengaruh kepada peserta didik pada saat terjadinya proses pembelajaran.(Priansa, 2014:79). Kesiapan guru/pendidik PAUD dapat dilihat dari pembuatan RPP oleh pendidik PAUD, karena RPP mencakup tema yang akan diberikan pada hari itu, alat peraga 
apa yang akan dipakai, waktu penyampaian tema berapa lama, metode yang akan dipakai dalam penyampaian tema, dan penilaian seperti apa yang akan diberikan, misalnya narasi atau bintang.

Guru sebagai model/teladan/panutan bagi peserta didik, karena pada pembelajaran di PAUD, anak usia dini belajar melalui panca indranya, yaitu apa yang dilihat dan di dengar akan ditiru oleh peserta didik di lembaga PAUD. Kegiatan belajar mengajar pada PAUD harus dilaksanakan dalam kondisi yang menyenangkan, aman, dan belajar melalui bermain. Pendidik/Guru PAUD harus memahami setiap tingkat perkembangan anak agar dapat memberikan stimulasi sesuai dengan usia dan perkembangan anak dengan optimal.

Oleh sebab itu, pendidik PAUD harus memiliki kompetensi pedagogic, professional, kepribadian, dan social. Kompetensi Pedagogik Pendidik PAUD, meliputi 1) Menguasai karakteristik peserta didik dari aspek fisik, moral, sosial, kultural, emosional, dan intelektual; 2) Menguasai teori belajar dan prinsip-prinsip pembelajaran yang mendidik; 3) Mengembangkan kurikulum yang terkait dengan bidang pengembangan yang diampu; 4)
Menyelenggarakan

kegiatan pengembangan yang mendidik; 5) Memanfaatkan teknologi informasi dan komunikasi untuk kepentingan penyelenggaran kegiatan pengembangan yang mendidik; 6) Memfasilitasi pengembangan potensi peserta didik untuk mengaktualisasikan berbagai potensi yang dimiliki; 7) Berkomunikasi secara efektif, empatik, dan sntun dengan peserta didik; 8) Menyelenggarakan penilaian dan evaluasi proses dan hasil belajar; 9) Memanfaatkan hasil penilaian dan evaluasi untuk kepentingan pembelajaran; dan 10) Melakukan tindakan reflektif untuk peningkatan kualitas pembelajaran.

\section{Kompetensi}

Kepribadian mencakup, 1) Bertindak sesuai dengan norma agama, hukum, sosial, dan kebudayaan nasional Indonesia; 2) Menampilkan diri sebagai pribadi yang jujur, berakhlak mulia, dan teladan bagi peserta didik dan masyarakat; 3) Menampilkan diri sebagai pribadi yang mantap, stabil, dewasa, arif, dan berwibawa; 4) Menunjukkan etos kerja, tanggung jawab yang tinggi, rasa bangga menjadi pendidik, dan rasa percaya diri; dan 5) Menjunjung tinggi kode etik profesi pendidik. Kompetensi Sosial meliputi, 1) Bersikap inklusif, bertindak 
obyektif, serta tidak diskriminatif karena pertimbangan jenis kelamin, agama, ras, kondisi fisik, latar belakang keluarga, dan status sosial ekonomi; 2) Berkomunikasi secara efektif, empatik, dan santun dengan sesama pendidik, tenaga kependidikan, orang tua, dan masyarakat; 3) Beradaptasi di tempat bertugas di seluruh wilayah Republik Indonesia yang memiliki keragaman sosial budaya; dan 4) Berkomunikasi dengan komunitas profesi sendiri dan profesi lain secara lisan dan tulisan atau bentuk lain.

\section{Sedangkan}

Kompetensi

Profesional mencakup, 1) Menguasai materi, struktur, konsep, dan pola pikir keilmuwan yang mendukung mata pelajaran yang diampu; 2) Menguasai standar kompetensi dan kompetensi dasar mata pelajaran/bidang pengembangan yang diampu; 3) Mengembangakn materi pelajaran yang diampu secara kreatif; 4) Mengembangkan keprofesionalan secara berkelanjutan dengan melakukan tindakan reflektif; dan 5) Memanfaatkan teknologi informasi dan komunikasi untuk berkomunikasi dan mengembangkan diri.

Keempat kompetensi tersebut sebagai dasar dan kesiapan guru/pendidik PAUD dalam melakukan kegiatan belajar di kelas. Tingkat capaian perkembangan anak yang harus diperhatikan dan dikuasai oleh pendidik PAUD, meliputi tingkat perkembangan agama dan nilainilai moral, fisik motoric, kognitif, bahasa, social emosional, dan seni. Tingkat capaian perkembangan anak tersebut berdasarkan usia anak usia dini yang dimulai dari 0 tahun sampai 6 (enam) tahun.

Kualifikasi akademik adalah tingkat pendidikan minimal yang harus dipenuhi oleh pendidik yang dibuktikan dengan ijazah dan atau sertifikasi. Berdasarkan standard nasional PAUD, Pasal 25, kualifikasi untuk guru PAUD adalah, memiliki ijazah D-IV atau S1 sarjana dalam bidang PAUD dan kependidikan lain yang relevan dengan system PAUD atau psikologi yang diperoleh dari program studi terakreditasi dan memiliki sertifikat Pendidikan Profesi Guru (PPG) PAUD dari perguruan tinggi terakreditasi. Pasal 26 menyatakan bahwa kualifikasi akademik guru pendamping yaitu memiliki ijazah D-IV atau S1 dalam bidang PAUD, dan kependidikan lain yang relevan dengan system PAUD, atau psikologi yang diperoleh dari program studi terakreditasi, atau memiliki ijazah D-II PGTK dari program studi terakreditasi. Pasal 27, menyebutkan bahwa, kualifikasi guru 
pendamping muda yaitu, memiliki ijazah Sekolah Menengah Atas (SMA) dan memiliki sertifikat pelatihan/pendidikan/kursus PAUD dari lembaga pemerintah yang kompeten.

\section{METODOLOGI}

Penelitian ini menggunakan pendekatan kualitatif yang digunakan untuk mengumpulkan dan menganalisa data yang diperoleh melalui FGD dan data sekunder. Pemilihan lokasi penelitian yaitu lembaga PAUD yang ada di Kota Bandung berdasarkan daerah yang memiliki LPTK dengan prodi PAUD. Responden adalah kepala TK, Pengelola KB, TPA, dan SPS beserta pendidik PAUD dari masing-masing lembaga PAUD. Jumlah responden sebanyak 8 lembaga PAUD yang terdiri dari 2 TK, 2 KB, 2 TPA, dan 2 SPS. Pengumpulan data dilakukan melalui focus group discussion (FGD) dan pemberian kuesioner. Penelitian ini dilakukan pada tahun 2016. Data dan informasi dianalisis sesuai dengan tujuan studi.

\section{HASIL DAN PEMBAHASAN}

Berdasarkan informasi yang diperoleh dari Dinas Pendidikan dan Kebudayaan Kota Bandung, jumlah lembaga PAUD yang ada di Kota Bandung berdasarkan satuan PAUD dan akreditasi dapat dilihat pada Tabel 1.3. di bawah ini. 
Tabel 1.3. Jumlah Lembaga PAUD berdasarkan Satuan PAUD dan Akreditasi

\begin{tabular}{|c|c|c|c|c|}
\hline \multirow[t]{2}{*}{ No. } & \multirow[t]{2}{*}{ Satuanp PAUD } & \multicolumn{2}{|c|}{ Jumlahp Lembagap P AUD } & \multirow[t]{2}{*}{ Total } \\
\hline & & Terakreditasi & Belum Terakreditasi & \\
\hline 1. & TK & 20 & 451 & 471 \\
\hline 2. & KB & 31 & 396 & 427 \\
\hline 3. & TPA & - & 12 & 12 \\
\hline 4. & SPS & 7 & 179 & 186 \\
\hline & Total & 58 & 1.038 & 1.096 \\
\hline
\end{tabular}


Tabel 1.3., di atas menunjukkan sebagian besar lembaga PAUD yaitu $94,71 \%$ belum terakreditasi. Artinya lembaga-lembaga PAUD tersebut masih di bawah standard nasional PAUD, karena belum mampu mencapai delapan standard PAUD.

Pengelola PAUD untuk mendapatkan pendidik PAUD melakukan rekrutmen yang bervariasi sesuai dengan kemampuan lembaga PAUD. Cara yang dilakukan untuk menyediakan pendidik PAUD, antara lain membuat pengumuman di depan lembaga PAUD, ada yang membuat iklan di Koran, tetapi ada juga yang pencari kerja datang langsung ke lembaga PAUD untuk mendaftar menjadi pendidik PAUD, bahkan mencari melalui bantuan teman.

Lembaga PAUD yang ternama atau sudah popular mungkin tidak akan mengalami kendala untuk mendapatkan pendidik PAUD yang berkualitas dan sesuai dengan standard pendidik dan tenaga kependidikan (PTK) PAUD yang terdapat dalam Peraturan Menteri Pendidikan dan Kebudayaan Nomor 137 Tahun 2014, tentang Standar Nasional PAUD. Sedangkan bagi lembaga PAUD yang kondisi kekuangannya lemah untuk mendapatkan pendidik PAUD sesuai standard agak sulit, karena terkait dengan gaji yang akan diberikan kepada pendidik PAUD tersebut.

Pada umumnya yang menjadi pendidik PAUD awal, adalah pendidik PAUD yang masih belum memahami apa itu PAUD dan dari latar belakang pendidikan yang beragam. Walaupun ada pendidik PAUD yang pernah mengikuti kursus PAUD, pada kenyataannya ada yang belum siap untuk mengajar. Hal ini diperkuat dari hasil diskusi dengan pengelola PAUD yang menyatakan, bahwa tidak semua calon pendidik PAUD yang ikut kursus begitu masuk lembaga PAUD menjadi pendidik PAUD dan sudah memiliki kompetensi yang memadai. Artinya kembali kepada pribadi pendidik tersebut, apakah dapat mengimplementasikan ilmu PAUD yang sudah didapat dari lembaga kursus pada proses pembelajarannya atau tidak. Terkadang mereka menguasai teorinya, tetapi ketika implementasinya mengalami kendala. Begitu pula yang terjadi pada lulusan dari Perguruan Tinggi dengan prodi PAUD atau lainnya. Mereka perlu penyesuaian dan perlu mendapatkan pelatihan, workshop, dan seminar baik itu secara intern atau tidak intern sebelum mereka terjun langsung untuk mengajar di dalam kelas. 
Kualifikasi akademik pendidik PAUD di Kota Bandung juga sangat beragam dan memiliki motivasi yang bervariasi pula. Pada umumnya pendidik PAUD khususnya untuk TPA dan SPS banyak yang menjadi guru sukarela. Mereka mengajar karena terpanggil untuk memberikan pembelajaran agar anak-anak usia dini yang ada di wilayahnya khususnya di Kota Bandung dapat terlayani oleh PAUD. Berikut jumlah pendidik/guru PAUD sampel berdasarkan kualifikasi akademik di Kota Bandung pada tahun 2016. 


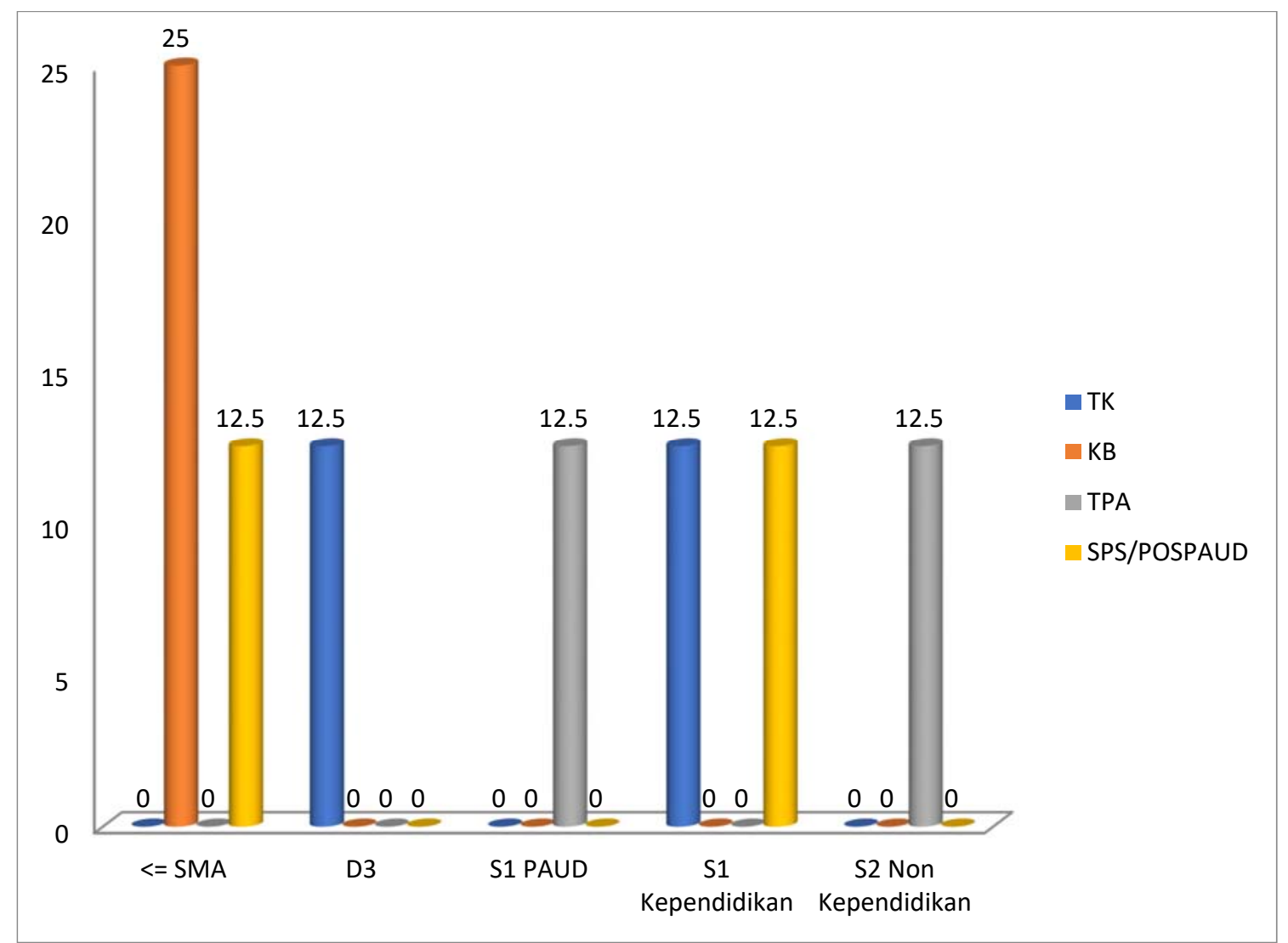

Gambar 1.1. Peresentase Kualifikasi Akademik Pendidik PAUD sampel di Kota Bandung pada tahun 2016. 
Gambar 1.1., di atas menunjukan bahwa kualifikasi yang banyak dimiliki oleh pendidik kelompok belajar (KB) sampel adalah SMA sederajat sebanyak $25 \%$. Untuk pendidik TPA sudah sarjana semuanya, namun pada S2 prodinya bukan PAUD atau Kependidikan sehingga tidak linier dengan PAUD. Artinya pemahaman mereka tentang PAUD masih kurang, sehingga pengelola TPA harus memberikan pelatihan, workshop, atau seminar tentang PAUD dan pengasuhan kepada mereka sebelum terjun mengajar ke dalam kelas. Selain itu, agar mereka dapat memberikan stimulasi perkembangan anak yang optimal. Hal tersebut diperkuat dari pendapat pendidik PAUD sampel yang menyatakan, bahwa mereka paham tentang PAUD setelah mengikuti pelatihan, workshop, seminar, dan bimtek PAUD. Artinya pemahaman tentang PAUD dan kompetensi pendidik PAUD akan bertambah/meningkat dengan adanya pelatihan, workshop, dan seminar yang berkesinambungan.

Ada empat kompetensi yang harus dikuasai oleh pendidik PAUD yaitu pedagogic, professional, kepribadian, dan social. Guru TK memiliki kemampuan kompetensi pedagogic hampir 100 persen, untuk kompetensi kepribadian kemampuan guru TK mencapai 58,33 persen. Sedangkan kemampuan kompetensi professional yang dimiliki oleh guru TK sudah mencapai 100 persen, dan 50 persen untuk kemampuan social. Kemampuan kompetensi guru KB sudah mencapai 100 persen untuk pedagogic, kepribadian, professional, dan social. Pendidik TPA memiliki kemampuan mencapai 100 persen untuk kompetensi social, sedangkan untuk kompetensi lainnya sebagian besar sangat mampu. Namun demikian, ada sebagian kecil pendidik TPA yang memiliki ketidakmampuan dalam kompetensi pedagogic. Kemampauan yang dimiliki oleh pendidik SPS sudah mencapai 100 persen pada kompetensi kepribadian dan professional. Sebagian besar pendidik SPS memiliki kemampuan sangat mampu pada kompetensi pedagogic dan social. Lebih jelasnya lihat pada Tabel 1.4. berikut ini. 
Tabel 1.4. Persentase Kompetensi yang dimiliki oleh pendidik PAUD ssampel di Kota Bandung.

\begin{tabular}{|c|c|c|c|c|c|c|c|c|c|c|c|c|c|c|c|c|}
\hline \multirow[b]{2}{*}{$\begin{array}{c}\text { Jenis } \\
\text { Kompetensi }\end{array}$} & \multicolumn{4}{|c|}{ TK (\%) } & \multicolumn{4}{|c|}{ KB (\%) } & \multicolumn{4}{|c|}{ ТРА (\%) } & \multicolumn{4}{|c|}{ SPS $(\%)$} \\
\hline & $\begin{array}{c}\text { Sanga } \\
\mathrm{t} \\
\text { Tidak } \\
\text { Mamp } \\
\mathrm{u} \\
\text { (STM } \\
\text { ) }\end{array}$ & $\begin{array}{c}\text { Tidak } \\
\text { Mamp } \\
\mathrm{u} \\
\text { (TM) }\end{array}$ & $\begin{array}{l}\text { Mamp } \\
\mathrm{u}(\mathrm{M})\end{array}$ & $\begin{array}{c}\text { Sanga } \\
\mathrm{t} \\
\text { Mamp } \\
\mathrm{u} \\
(\mathrm{SM})\end{array}$ & $\begin{array}{c}\text { Sanga } \\
\mathrm{t} \\
\text { Tidak } \\
\text { Mamp } \\
\mathrm{u} \\
\text { (STM } \\
\text { ) }\end{array}$ & $\begin{array}{c}\text { Tidak } \\
\text { Mamp } \\
\text { u } \\
\text { (TM) }\end{array}$ & $\begin{array}{l}\text { Mamp } \\
\text { u (M) }\end{array}$ & $\begin{array}{c}\text { Sanga } \\
\mathrm{t} \\
\text { Mamp } \\
\mathrm{u} \\
(\mathrm{SM})\end{array}$ & $\begin{array}{c}\text { Sanga } \\
\mathrm{t} \\
\text { Tidak } \\
\text { Mamp } \\
\mathrm{u} \\
\text { (STM } \\
\text { ) }\end{array}$ & $\begin{array}{c}\text { Tidak } \\
\text { Mamp } \\
\text { u } \\
\text { (TM) }\end{array}$ & $\begin{array}{l}\text { Mamp } \\
\mathrm{u}(\mathrm{M})\end{array}$ & $\begin{array}{c}\text { Sanga } \\
\mathrm{t} \\
\text { Mamp } \\
\mathrm{u} \\
(\mathrm{SM})\end{array}$ & $\begin{array}{c}\text { Sanga } \\
\mathrm{t} \\
\text { Tidak } \\
\text { Mamp } \\
\mathrm{u} \\
\text { (STM } \\
\text { ) }\end{array}$ & $\begin{array}{c}\text { Tidak } \\
\text { Mamp } \\
\text { u } \\
(\mathrm{TM})\end{array}$ & $\begin{array}{l}\text { Mamp } \\
\mathrm{u}(\mathrm{M})\end{array}$ & $\begin{array}{c}\text { Sanga } \\
\mathrm{t} \\
\text { Mamp } \\
\mathrm{u} \\
(\mathrm{SM})\end{array}$ \\
\hline Pedagogik & 0 & 0 & 94.12 & 5.88 & 0 & 0 & 100 & 0 & 0 & 1.47 & 17.65 & 80.88 & 0 & 0 & 41.18 & 58.82 \\
\hline Kepribadian & 0 & 0 & 58.33 & 41.67 & 0 & 0 & 100 & 0 & 0 & 0 & 33.33 & 66.67 & 0 & 0 & 0 & 100 \\
\hline Profesional & 0 & 0 & 100 & 0 & 0 & 0 & 100 & 0 & 0 & 0 & 6.25 & 93.75 & 0 & 0 & 100 & \\
\hline Sosial & 0 & 0 & 50 & 50 & 0 & 0 & 100 & 0 & 0 & 0 & 0 & 100 & 0 & 0 & 42.86 & 57.14 \\
\hline
\end{tabular}


Aspek kompetensi pedagogik yang tidak mampu dikuasai oleh guru TPA yaitu, tidak mampu dalam melaksanakan program remedial dan pengayaan. Hal ini, mengindikasikan bahwa masih ada sebagian kecil pendidik TPAbelum menetapkan standar kelulusan minimal (SKL). Oleh sebab itu perlu ada pelatihan khusus mengenai program remedial dan pemberian pengayaan.

\section{SIMPULAN}

Belum semua pengelola PAUD di Kota Bandung dapat melakukan rekrutmen melalui iklan baris di Koran, karena berhubungan dengan kondisi keuangan lembaga PAUD yang berbedabeda. Kualifikasi akademik pendidik PAUD masih didominasi dari lulusan SMA di lembaga KB dan sarjana di TPA. Kompetensi yang masih tidak dikuasi oleh pendidik TPA adalah komponen yang ada dalam kompetensi pedagogic. Kesiapan pendidik PAUD dalam mengajar terletak pada penguasaan kompetensi dengan adanya pelatihan, workshop, seminar yang diberikan oleh lembaga PAUD.

\section{DAFTAR PUSTAKA}

Juni Donni Priansa. 2014. Kinerja dan Profesionalisme Guru. Bandung: PT. Alfabeta.

Peraturan Menteri Pendidikan dan Kebudayaan Nomor 137 Tahun 2014, Tentang Standar Nasional PAUD.

Slameto. 2010. Belajar dan Faktor yang Mempengaruhinya. Jakarta: Rineka Cipta.

Sri Kuswahyuni. 2009. Pengaruh Bimbingan Kelompok terhadap Kesiapan Menghadapi Ujian Akhir pada Siswa Kelas VI A3 SDN Sendang Mulyo 03 Semarang Tahun Ajaran 2008/2009. Skripsi. Semarang : IKIP PGRI Semarang

Oemar Hamalik. 2006. Proses Belajar Mengajar. Jakarta: PT. Bumi Aksara 